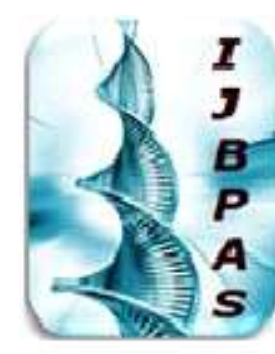

International Journal of Biology, Pharmacy and Allied Seiences (IJBPAS) 'A Bridge Betusen Caboratory and Qqude' WwW.ijbpas.com

\title{
COMMON TRENDS IN PRESCRIBING ANALGESICS FOR PULPITIS
}

\section{ABIGAIL RANASINGHE ${ }^{1}$, DHANRAJ GANAPATHY ${ }^{2 *}$, SUBHASHREE $\mathbf{R}^{3}$ AND RAKSHAGAN V $\mathbf{V}^{4}$}

1: Saveetha Dental College and Hospitals, Saveetha Institute of Medical and Technical Sciences, Saveetha University, Chennai, India

2: Professor and Head of Department, Department of Prosthodontics, Saveetha Institute of Medical and Technical Sciences, Saveetha University, Chennai, India

3: Senior Lecturer, Department of Prosthodontics, Saveetha Dental College and Hospitals, Saveetha Institute of Medical and Technical Sciences, Saveetha University, Chennai -77

4: Senior Lecturer, Department of Prosthodontics, Saveetha Dental College and Hospitals Saveetha Institute of Medical and Technical Sciences, Saveetha University, Chennai -77

*Corresponding Author: E Mail: Dr. Dhanraj Ganapathy: dhanraj@saveetha.com

Received 19 ${ }^{\text {th }}$ March 2021; Revised 20 ${ }^{\text {th }}$ April. 2021; Accepted $19^{\text {th }}$ May 2021; Available online $1^{\text {st }}$ Aug. 2021

https://doi.org/10.31032/IJBPAS/2021/10.8.1037

ABSTRACT

Pulpits is a condition that causes painful inflammation of the pulp. It can occur in one or more teeth, and is caused by bacteria that invade the tooth's pulp, causing it to swell. There are two forms of pulpitis: reversible and irreversible. The relief and management of pain by the operator reflects the quality of treatment given thus providing the patient comfort and an improved quality of life. Hence it is extremely important for dentists to have a thorough knowledge on analgesics and their effects in order to correctly prescribe the drug based on the amount of pain experienced by the patient. This study aimed to find the pattern of analgesics prescribed by undergraduate students for irreversible pulpitis and apical periodontitis. In order to determine the common trends in prescribing analgesics for pulpitis and also in order to create awareness a questionnaire comprising 15 questions was prepared. This survey based study was carried between the month of December- January 2020. This survey was carried out with the help of an online platform. 
Around 100 undergraduate students participated in this survey. Based on the responses, data was collected and tabulated in an Excel sheet. This was followed by transferring the Excel tabulated data to SPSS for data analysis. Based on the analysis the results were tabulated.

In this study the commonly prescribed analgesic for pulpitis was found to be zerodol p $50 \%$ followed by acetaminophen $30 \%$ and ibuprofen $20 \%$. Majority of the students preferred to prescribe non opioids $70 \%$ whereas the remaining 30\% preferred opioids. More than half of the participants prescribed antibiotics like amoxicillin $500 \mathrm{mg} 3$ times a day for a duration of 57 days (58\%). The most common side effect of NSAIDS was found to be gastric erosion (50\%) Majority of the students stated that the abbreviated name is an error faced while prescribing analgesics $(50 \%)$ Within the limitations of the study, Prescribing Non opioids were preferred rather than prescribing opioids in case of pulpitis and the most frequently prescribed drug was found to be zerodol p. However, undergraduate students faced errors while prescribing medicines. Gradual experience and vigilant supervision on prescription patterns of medicines can overcome such errors in future.

\section{Keywords: Analgesics, root canals, pulpitis}

\section{INTRODUCTION}

General population generally seeks dental treatment due to pain or swelling and pain of odontogenic origin (Keiser and Hargreaves, 2002). Most of the conditions are treated by conventional management such as operative procedures, e.g. nonsurgical root canal treatment, Most conditions can be treated by conventional management such as operative procedures, e.g. extraction, dental filling or nonsurgical root canal treatment which includes pulp extirpation, instrumentation, and intracanal medication. In several cases, analgesics and/or antibiotics are indicated as adjuncts to conventional endodontic procedures (Siqueirajr and Rocas, 2005).
Analgesics are "the drugs that selectively relieves pain by acting in the central nervous system (CNS) or on peripheral pain mechanisms, without altering consciousness". Analgesics are further divided into two groups : Non opioid / aspirin like / NSAIDs analgesics and Opioid / narcotic / morphine like analgesics (Becker and Phero, 2005). Nonopioids include acetaminophen and the nonsteroidal anti-inflammatory drugs (NSAIDs), which interrupt prostaglandin synthesis and also have a maximal dose or ceiling for their analgesic effect. NSAIDs are generally useful in the initial management of pain that has an inflammatory component 
including pain associated with invade the tooth's pulp, causing it to swell. musculoskeletal trauma and dentistry. There are two forms of pulpitis: reversible NSAIDs inhibit cyclooxygenase (COX) and irreversible (Attar et al., 2008). activity thereby inhibiting synthesis of Endodontic infections are polymicrobial in thromboxanes, prostaglandins and prostacyclin (Slaus and Bottenberg, 2002). Analgesic is administered considering the cause and nature of pain (mild, moderate or severe ; acute or chronic ; ratio of pain ; inflammation) along with risk factors in the given patient, considering past experience of the patient, acceptability to given drug and individual preference. Patients differ in their analgesic response to different NSAIDs (Fernandes and Ataide, 2010).

Analgesics are considered one of the most important drugs groups in dental practice considering the prescription rate, costeffectiveness, clinical efficacy and safety profile of this drug grou (Dionne et al., 1983). There are different approaches to develop treatment guidelines for dental pain treatment in order to rationalize the use of analgesics (Rousseau et al., 2002). The rationalization of analgesics use is an ongoing challenge, since some analgesics are over-the-counter (OTC) drugs and can be taken without medical prescription.

Pulpits is a condition that causes painful inflammation of the pulp. It can occur in one or more teeth, and is caused by bacteria that nature and obligate anaerobic bacteria are considered as the dominant microflora in primary infections. The endodontic treatment is eradication of the infection and prevention of microorganisms from infecting or reinfecting the root and/or periradicular tissues (Whitten et al., 1996). The relief and management of pain by the operator reflects the quality of treatment given thus providing the patient comfort and an improved quality of life. Hence it is extremely important for dentists to have a thorough knowledge on analgesics and their effects in order to correctly prescribe the drug based on the amount of pain experienced by the patient (Narayanan and Vaishnavi, 2010). Most of the studies on medication pattern involve qualified dentists. Previously our team has a rich experience in working on various research projects across multiple disciplines. (Muthukrishnan and Warnakulasuriya, 2018), (Govindaraju, Neelakantan and Gutmann, 2017), (Chen et al., 2019), (Priyanka et al., 2017), (Sitharthan et al., 2019), (Priyadharsini et al., 2018), (Azeem and Sureshbabu, 2018), (Wu et al., 2019), (Abitha and Santhanam, 2019), (Manohar 
and Abilasha, 2019), (Venu, Dhana Raju and Subramani, 2019), (Wang et al., 2019), (Girija, Jayaseelan and Arumugam, 2018), (Sheriff, Ahmed Hilal Sheriff and Santhanam, 2018), (Dhinesh et al., 2017). Now the growing trend in this area motivated us to pursue this project.

Limited data is available on dental undergraduates. Students need to acquire correct prescribing skills. Hence clinical instructors of dental schools take technical skills as the primary component of a 'good' dentist (Siqueira and Rôças, 2014). Dental students are not allowed to prescribe medicines on their own, but only under supervision of clinical teachers.

\section{MATERIALS AND METHODS}

In order to determine the common trends in prescribing analgesics for pulpitis and also in order to create awareness a questionnaire comprising 15 questions was prepared. This survey based study was carried between the month of December- January 2020. This survey was carried out with the help of an online platform. Around 100 undergraduate students participated in this survey. Sample randomised sampling method was used to categorise sampling population. The survey was conducted through an online portal. 100 participants who had the ability to give informed consent were included in this survey. In order to avoid multiple attempts of a single participant demographic details such as name, gender, Email ID was made mandatory to mention by the participants before taking up the survey.

Based on the responses, data was collected and tabulated in an Excel sheet. This was followed by transferring the Excel tabulated data to SPSS for data analysis. Based on the analysis the results were tabulated.

\section{RESULTS AND DISCUSSION}

In this study the commonly prescribed analgesic for pulpitis was found to be zerodol p $50 \%$ followed by acetaminophen $30 \%$ and ibuprofen 20\% (Figure 1). This is in accordance with the study of Umar et al 2013. He stated that zerodol $P$ is the drug of choice followed by acetaminophen (Kumar et al., 2013)). Zerodol $P$ is a combination of aceclofenac and acetaminophen which acts by blocking the action of chemical messengers responsible for pain fever and inflammation. However, this finding of our study does not go in hand with the study SJ KIA et al 2013. According to him acetaminophen is the most frequently used in case of pulpitis (Kia et al., 2013). Factors like different intensity of pain and swelling may be the reason behind this finding. Difference in geographic location could also 
contribute towards the selection of analgesics.

Majority of the students preferred non opioids $70 \%$ whereas the remaining $30 \%$ preferred opioids (Figure 2). This is in accordance with previous studies Weeks LM et al 2016, stated that non opioids were preferred than opioids (Weekes, 2016). This is due to the public health issues like opioid misuse and abuse and also due to pharmaceutical opioid poisoning.

More than half of the participants prescribed antibiotics like amoxicillin $500 \mathrm{mg} 3$ times a day for a duration of 5- 7 days ( $58 \%$ ) or metronidazole $20 \%$ along with analgesics Whereas the remaining students did not prescribe antibiotics (Figure 3). This is in accordance with previous studies. Germack et al 2017 reveal that amoxicillin (83\%) was the most commonly prescribed antibiotic along with analgesics followed by metronidazole (17\%) (Germack et al., 2017). It is universally accepted that antibiotics are indicated in case of infection or signs of systemic involvement. Necrotic pulp with acute apical periodontitis, swelling and moderate/severe preoperative symptoms are some common conditions identified for antibiotic therapy (Mainjot et al., 2009).

The most common side effect of NSAIDS was found to be gastric erosion $(50 \%)$ followed by prolonged bleeding time $(20 \%)$ followed by hepatotoxicity ( $20 \%$ ) and nausea $(10 \%)$. This is in accordance with the study of Sarkar et al 2014. He stated that frequent side effects attributed to NSAIDs are gastrointestinal in nature, which includes dyspepsia, gastric erosions, and mucosal ulcerations. Besides, NSAIDs exert an antiplatelet effect prolonging bleeding time. Hence NSAIDs should be avoided in patients taking anticoagulants, such as warfarin, or those suffering bleeding disorders (Sarkar, Das and Baral, 2004). Our institution is passionate about high quality evidence based research and has excelled in various fields ((Pc, Marimuthu and Devadoss, 2018; Ramesh et al., 2018; Vijayashree Priyadharsini, Smiline Girija and Paramasivam, 2018; Ezhilarasan, Apoorva and Ashok Vardhan, 2019; Ramadurai et al., 2019; Sridharan et al., 2019; Vijayashree Priyadharsini, 2019; Chandrasekar et al., 2020; Mebin George Mathew et al., 2020; $\mathrm{R}$ et al., 2020; Samuel, 2021). We hope this study adds to this rich legacy.

Majority of the students stated that the abbreviated name is an error faced while prescribing analgesics (50\%) followed by incorrect strength $(30 \%)$ and incorrect dose $(20 \%)$. This finding goes in hand with the 
study of Buck et al 2000. According to his study he stated that the abbreviated name is the most common error faced by dental students. which could be avoided with gradual practice and experience (Buck et al., 2000). Our institution is passionate about high quality evidence based research and has excelled in various fields (Pc, Marimuthu and Devadoss, 2018; Ramesh et al., 2018;

Ezhilarasan, Apoorva and Ashok Vardhan, 2019; Ramadurai et al., 2019; Sridharan et al., 2019; Vijayashree Priyadharsini, 2019; M. G. Mathew et al., 2020). We hope this study adds to this rich legacy.

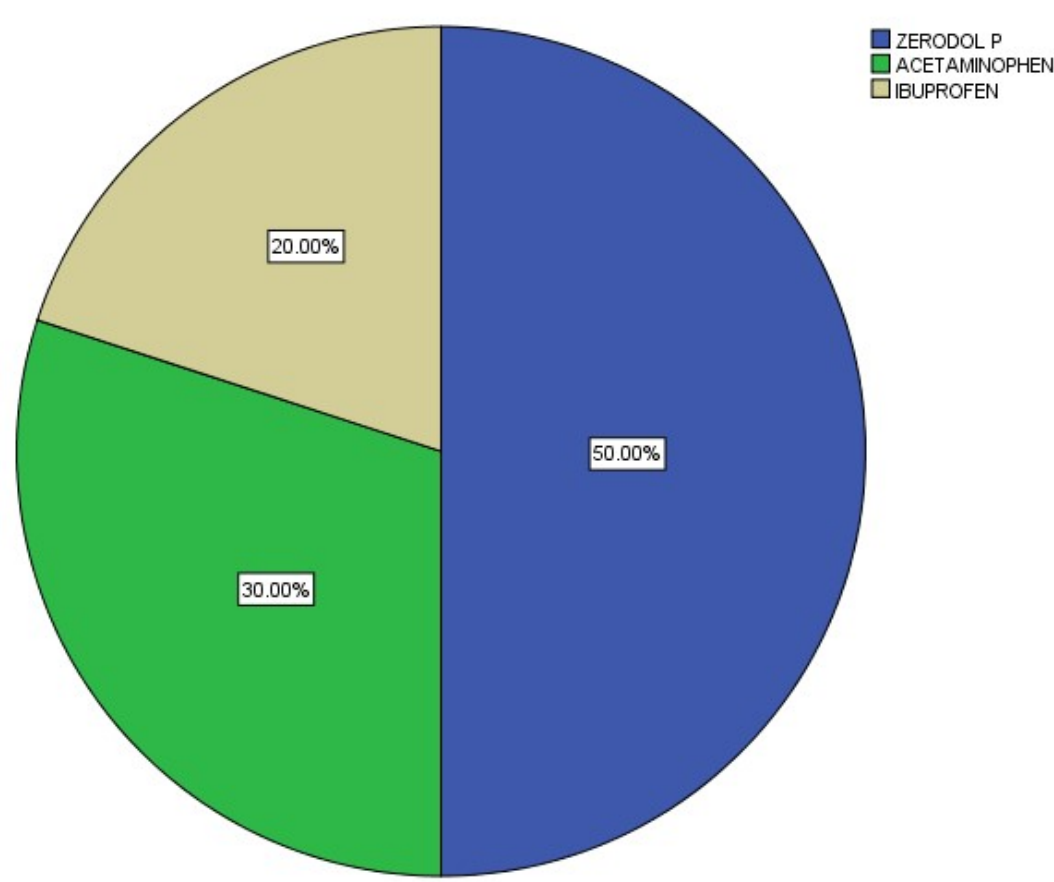

Figure 1: The pie chart shows the percentage responses by participants for the most commonly prescribed analgesic in case of pulpitis. Blue colour represents Zerodol p (50\%).Green represents acetaminophen $(30 \%)$. Beige represents ibuprofen $(20 \%)$. 


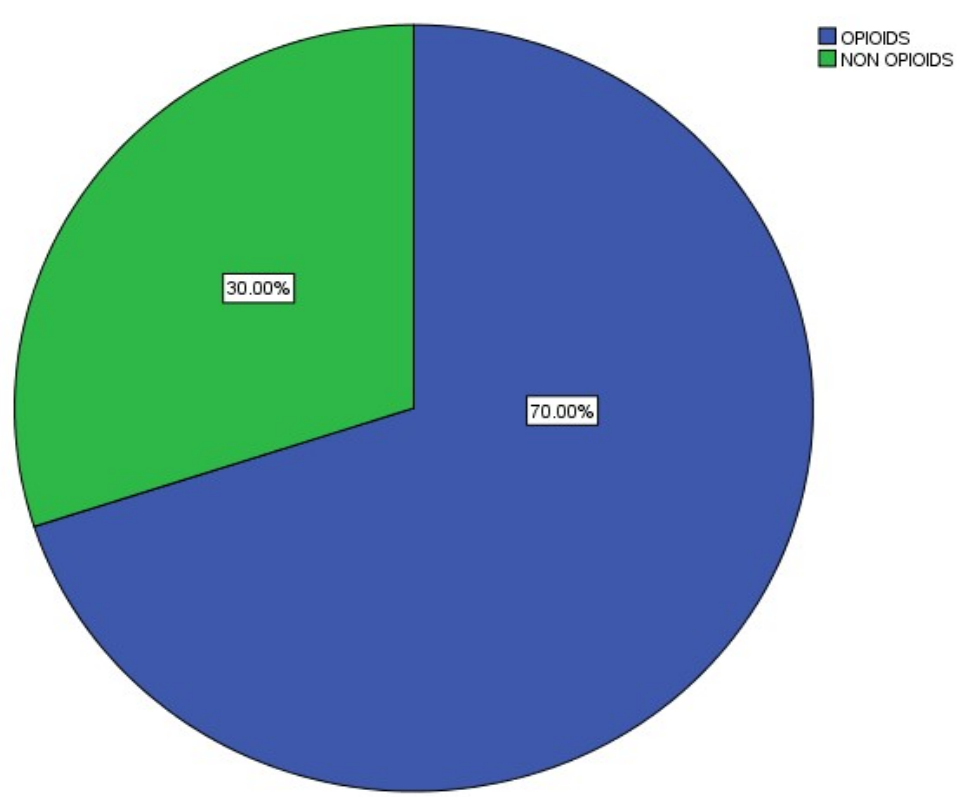

Figure 2: The pie chart shows the percentage responses by participants for prescribing opioids or non opioids in case of pulpitis.Blue colour represent Non opioids $(70 \%)$ and green represents opioids $(30 \%)$.

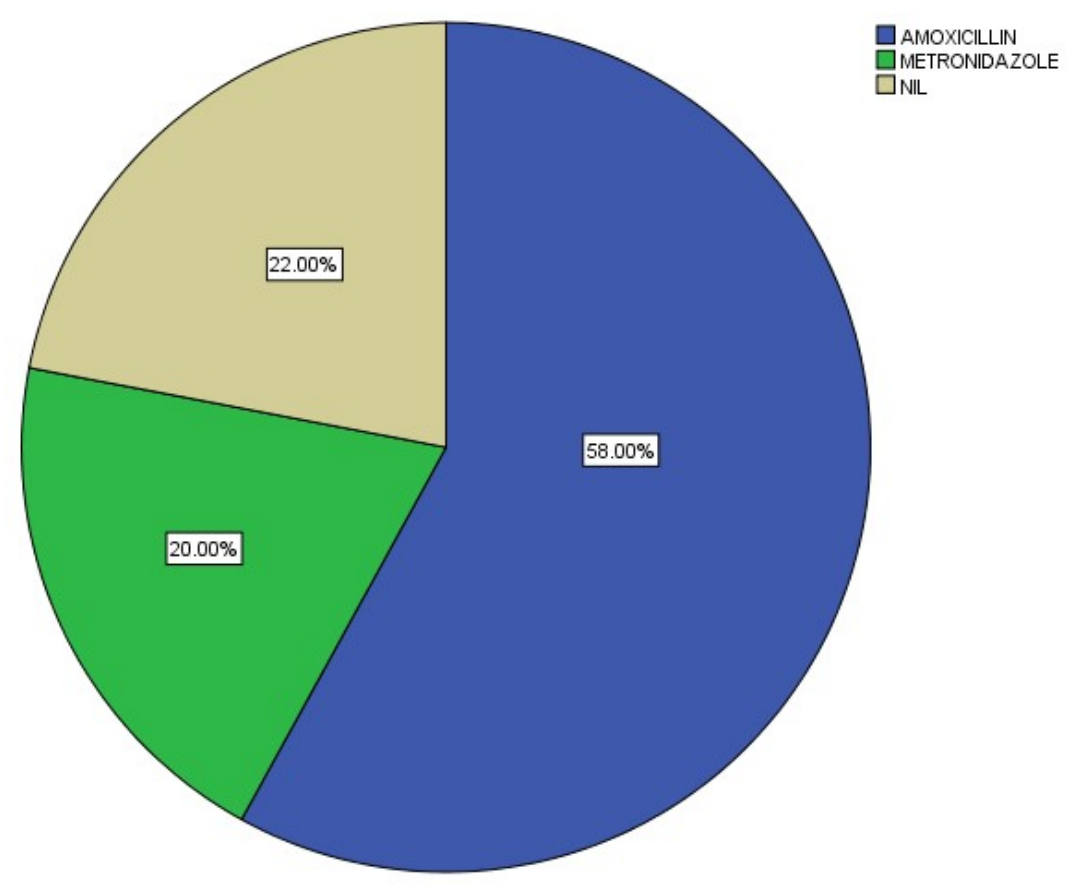

Figure 3: The pie chart shows the percentage responses by participants for antibiotics prescribed along with analgesics . Blue colour represents amoxicillin $(\mathbf{5 8 \%})$. Beige represents metronidazole $(\mathbf{2 2 \%})$. Green represents nil 


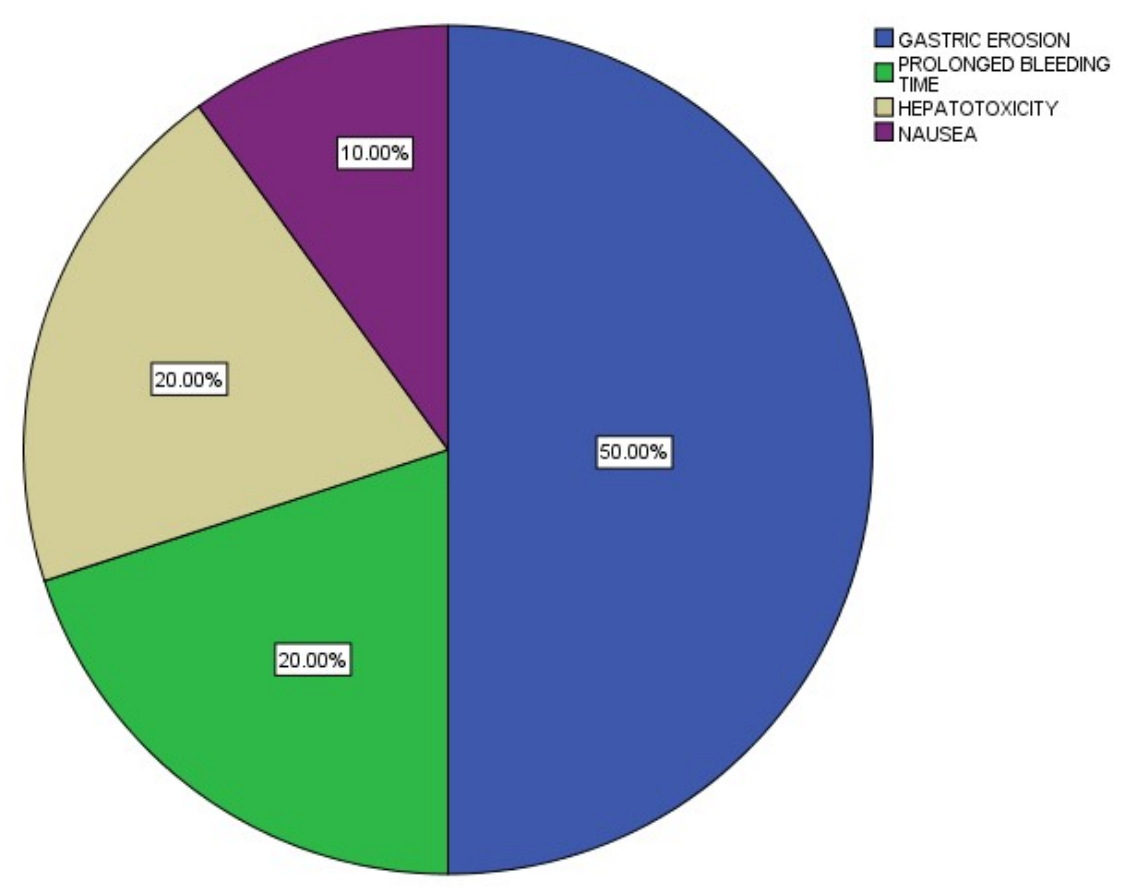

Figure 4: The pie chart shows the percentage responses by participants for the most common side effects of NSAIDS. Blue colour represents gastric erosion $(\mathbf{5 0} \%)$. Green represents prolonged bleeding time $(\mathbf{2 0} \%)$. Beige represents hepatotoxicity (20\%). Purple represents nausea.

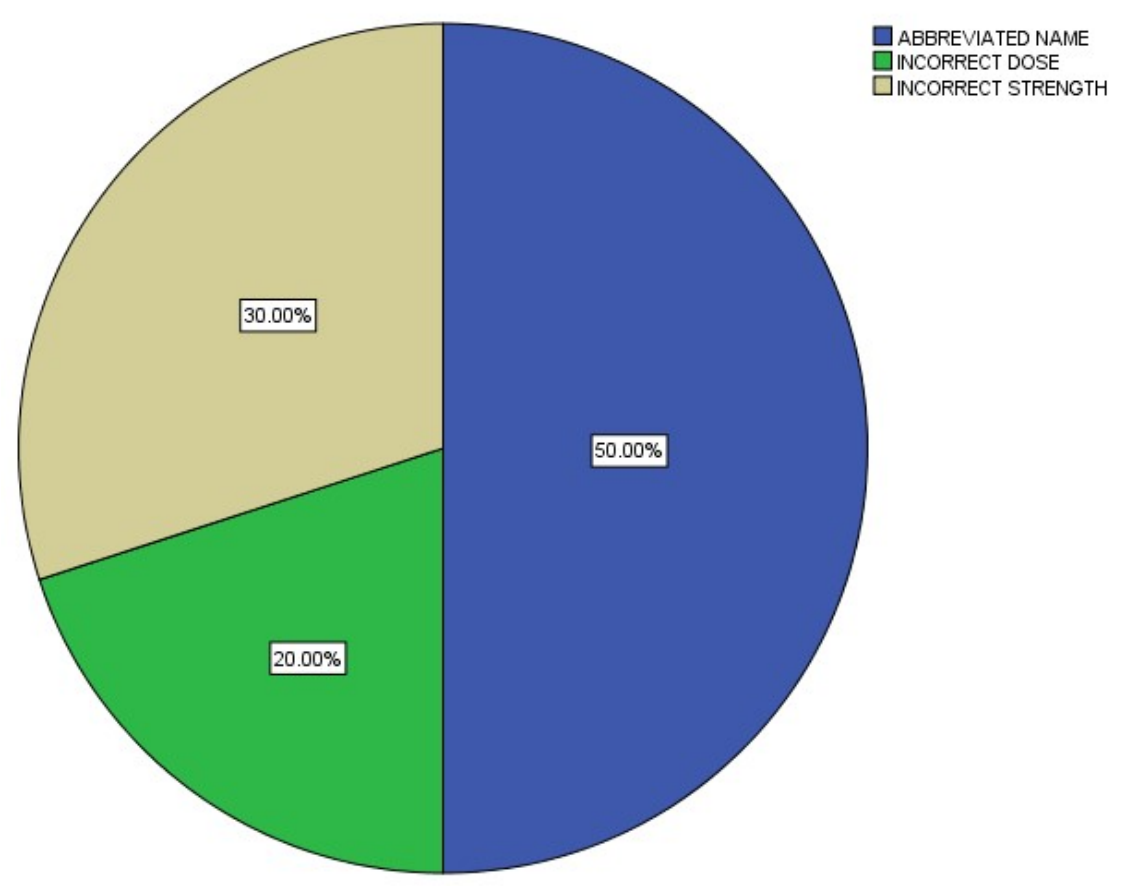

Figure 5: The pie chart shows the percentage responses by participants for the most common error faced while prescribing analgesics . Blue colour represents abbreviated name $(50 \%)$. Green represents incorrect dose $(20 \%)$ and beige represents incorrect strength $(30 \%)$. 


\section{CONCLUSION}

Within the limitations of the study, Prescribing Non opioids were preferred rather than prescribing opioids in case of pulpitis and the most frequently prescribed drug was found to be zerodol p. However, undergraduate students faced errors while prescribing medicines. Gradual experience and vigilant supervision on prescription patterns of medicines can overcome such errors in future.

\section{ACKNOWLEDGEMENT}

The authors of this study would like to express their gratitude towards everyone who facilitated and enabled us to carry out this study successfully.

\section{CONFLICT OF INTEREST}

None declared.

\section{REFERENCES}

[1] Abitha, T. and Santhanam, A. (2019) 'Correlation between bizygomatic and maxillary central incisor width for gender identification', Brazilian Dental Science. Available at: https://bds.ict.unesp.br/index.php/cob /article/view/1775.

[2] Attar, S. et al. (2008) 'Evaluation of Pretreatment Analgesia and Endodontic Treatment for Postoperative Endodontic Pain', Journal of Endodontics, pp. 652-655. doi: 10.1016/j.joen.2008.02.017.

[3] Azeem, R. A. and Sureshbabu, N. M. (2018) 'Clinical performance of direct versus indirect composite restorations in posterior teeth: A systematic review', Journal of conservative dentistry: JCD, 21(1), pp. 2-9.

[4] Becker, D. E. and Phero, J. C. (2005) 'Drug Therapy in Dental Practice: Nonopioid and Opioid Analgesics', Anesthesia Progress, pp. 140-149. doi: 10.2344/00033006(2005)52[140:dtd]2.0.co;2.

[5] Buck, D. et al. (2000) 'What makes a good dentist and do recent trainees make the grade? The views of vocational trainers', British Dental Journal, pp. 563-566. doi: 10.1038/sj.bdj.4800829a.

[6] Chandrasekar, R. et al. (2020) 'Development and validation of a formula for objective assessment of cervical vertebral bone age', Progress in orthodontics, 21(1), p. 38.

[7] Chen, F. et al. (2019) '6-shogaol, a active constiuents of ginger prevents UVB radiation mediated inflammation and oxidative stress through modulating $\mathrm{NrF} 2$ signaling in human epidermal keratinocytes 
(HaCaT cells)', Journal of photochemistry and photobiology. B, Biology, 197, p. 111518.

[8] Dhinesh, B. et al. (2017) 'An experimental analysis on the influence of fuel borne additives on the single cylinder diesel engine powered by Cymbopogon flexuosus biofuel', Journal of the Energy Institute, 90(4), pp. 634-645.

[9] Dionne, R. A. et al. (1983) 'Suppression of Postoperative Pain by Preoperative Administration of Ibuprofen in Comparison to Placebo, Acetaminophen, and Acetaminophen Plus Codeine', The Journal of Clinical Pharmacology, pp. 37-43. doi: 10.1002/j.15524604.1983.tb02702.x.

[10] Ezhilarasan, D., Apoorva, V. S. and Ashok Vardhan, N. (2019) 'Syzygium cumini extract induced reactive oxygen species-mediated apoptosis in human oral squamous carcinoma cells', Journal of oral pathology \& medicine: official publication of the International Association of Oral Pathologists and the American Academy of Oral Pathology, 48(2), pp. 115-121.

[11] Fernandes, M. and Ataide, I. (2010)
'Nonsurgical management of periapical lesions', Journal of Conservative Dentistry, p. 240. doi: 10.4103/0972-0707.73384.

[12] Germack, M. et al. (2017) 'Antibiotic Use in 2016 by Members of the American Association of Endodontists: Report of a National Survey', Journal of Endodontics, pp. 1615-1622. doi: 10.1016/j.joen.2017.05.009.

[13] Girija, S. A., Jayaseelan, V. P. and Arumugam, P. (2018) 'Prevalence of VIM- and GIM-producing Acinetobacter baumannii from patients with severe urinary tract infection', Acta microbiologica et immunologica Hungarica, 65(4), pp. 539-550.

[14] Govindaraju, L., Neelakantan, P. and Gutmann, J. L. (2017) 'Effect of root canal irrigating solutions on the compressive strength of tricalcium silicate cements', Clinical oral investigations, 21(2), pp. 567-571.

[15] Keiser, K. and Hargreaves, K. M. (2002) 'Building effective strategies for the management of endodontic pain', Endodontic Topics, pp. 93105. doi: 10.1034/j.16011546.2002.30109.x. 
[16] Kia, S. J. et al. (2013) 'Evaluation of Drug Prescription Pattern among General Dental Practitioners in Rasht, Iran', Journal of Dentomaxillofacial Radiology, Pathology and Surgery, pp. 18-23. doi: 10.18869/acadpub.3dj.1.2.18.

[17] Kumar, K. P. et al. (2013) 'Antibiotic Prescribing Habits of Dental Surgeons in Hyderabad City, India, for Pulpal and Periapical Pathologies: A Survey', Advances in Pharmacological Sciences, pp. 1-4. doi: $10.1155 / 2013 / 537385$.

[18] Mainjot, A. et al. (2009) 'Antibiotic prescribing in dental practice in Belgium', International Endodontic Journal, pp. 1112-1117. doi: 10.1111/j.1365-2591.2009.01642.x.

[19] Manohar, J. and Abilasha, R. (2019) 'A Study on the Knowledge of Causes and Prevalance of Pigmentation of Gingiva among Dental Students', Indian Journal of Public Health Research \& Development, p. 95 . doi: 10.5958/0976-5506.2019.01859.x.

[20] Mathew, M. G. et al. (2020) 'Evaluation of adhesion of Streptococcus mutans, plaque accumulation on zirconia and stainless steel crowns, and surrounding gingival inflammation in primary ...', Clinical oral investigations. Available at: https://link.springer.com/article/10.1 007/s00784-020-03204-9.

[21] Mathew, M. G. et al. (2020) 'Evaluation of adhesion of Streptococcus mutans, plaque accumulation on zirconia and stainless steel crowns, and surrounding gingival inflammation in primary molars: Randomized controlled trial', Clinical oral investigations, pp. 1-6.

[22] Muthukrishnan, A. and Warnakulasuriya, S. (2018) 'Oral health consequences of smokeless tobacco use', The Indian journal of medical research, 148(1), pp. 3540.

[23] Narayanan, L. and Vaishnavi, C. (2010) 'Endodontic microbiology', Journal of Conservative Dentistry, p. 233. doi: 10.4103/09720707.73386.

[24] Pc, J., Marimuthu, T. and Devadoss, P. (2018) 'Prevalence and measurement of anterior loop of the mandibular canal using CBCT: A cross sectional study', Clinical 
implant dentistry and related research. Available at: https://europepmc.org/article/med/2 9624863.

[25] Priyadharsini, J. V. et al. (2018) 'In silico analysis of virulence genes in an emerging dental pathogen A. baumannii and related species', Archives of Oral Biology, pp. 9398. doi: 10.1016/j.archoralbio.2018.07.001.

[26] Priyanka, S. et al. (2017) 'Detection of cytomegalovirus, Epstein-Barr virus, and Torque Teno virus in subgingival and atheromatous plaques of cardiac patients with chronic periodontitis', Journal of Indian Society of Periodontology, 21(6), pp. 456-460.

[27] Ramadurai, N. et al. (2019) 'Effectiveness of 2\% Articaine as an anesthetic agent in children: randomized controlled trial', Clinical oral investigations, 23(9), pp. 3543-3550.

[28] Ramesh, A. et al. (2018) 'Comparative estimation of sulfiredoxin levels between chronic periodontitis and healthy patients A case-control study', Journal of periodontology, 89(10), pp. 1241-
1248.

[29] R, H. et al. (2020) 'CYP2 C9 polymorphism among patients with oral squamous cell carcinoma and its role in altering the metabolism of benzo[a]pyrene', Oral Surgery, Oral Medicine, Oral Pathology and Oral Radiology, pp. 306-312. doi: 10.1016/j.oooo.2020.06.021.

[30] Rousseau, W. et al. (2002) 'A Comparison of Pain Levels During Pulpectomy, Extractions, and Restorative Procedures', Journal of Endodontics, pp. 108-110. doi: 10.1097/00004770-20020200000015.

[31] Samuel, S. R. (2021) 'Can 5-yearolds sensibly self-report the impact of developmental enamel defects on their quality of life?', International journal of paediatric dentistry / the British Paedodontic Society [and] the International Association of Dentistry for Children, 31(2), pp. 285-286.

[32] Sarkar, C., Das, B. and Baral, P. (2004) 'Analgesic use in dentistry in a tertiary hospital in western Nepal', Pharmacoepidemiology and Drug Safety, pp. 729-733. doi: 10.1002/pds.972. 
[33] Sheriff, K. A. H., Ahmed Hilal Sheriff, K. and Santhanam, A. (2018) 'Knowledge and Awareness towards Oral Biopsy among Students of Saveetha Dental College', Research Journal of Pharmacy and Technology, p. 543. doi: $10.5958 / 0974$ 360x.2018.00101.4.

[34] Siqueira, J. F. and Rôças, I. N. (2014) 'Present status and future directions in endodontic microbiology', Endodontic Topics, pp. 3-22. doi: 10.1111/etp.12060.

[35] Siqueirajr, J. and Rocas, I. (2005) 'Exploiting Molecular Methods to Explore Endodontic Infections: Part 2-Redefining the Endodontic Microbiota', Journal of Endodontics, pp. 488-498. doi: 10.1097/01.don.0000157990.86638. 49.

[36] Sitharthan, R. et al. (2019) 'Automated power management strategy for wind power generation system using pitch angle controller', Measurement and Control, 52(3-4), pp. 169-182.

[37] Slaus, G. and Bottenberg, P. (2002) 'A survey of endodontic practice amongst Flemish dentists',
International Endodontic Journal, pp. 759-767. doi: 10.1046/j.13652591.2002.00564.x.

[38] Sridharan, G. et al. (2019) 'Evaluation of salivary metabolomics in oral leukoplakia and oral squamous cell carcinoma', Journal of oral pathology \& medicine: official publication of the International Association of Oral Pathologists and the American Academy of Oral Pathology, 48(4), pp. 299-306.

[39] Venu, H., Dhana Raju, V. and Subramani, L. (2019) 'Combined effect of influence of nano additives, combustion chamber geometry and injection timing in a DI diesel engine fuelled with ternary (dieselbiodiesel-ethanol) blends', Energy, pp. 386-406. doi: 10.1016/j.energy.2019.02.163.

[40] Vijayashree Priyadharsini, J. (2019) 'In silico validation of the nonantibiotic drugs acetaminophen and ibuprofen as antibacterial agents against red complex pathogens', Journal of periodontology, 90(12), pp. 1441-1448.

[41] Vijayashree Priyadharsini, J., Smiline Girija, A. S. and 
Paramasivam, A. (2018) 'In silico analysis of virulence genes in an emerging dental pathogen A. baumannii and related species', Archives of oral biology, 94, pp. 9398.

[42] Wang, Y. et al. (2019) 'Synthesis of Zinc oxide nanoparticles from Marsdenia tenacissima inhibits the cell proliferation and induces apoptosis in laryngeal cancer cells (Hep-2)', Journal of photochemistry and photobiology. B, Biology, 201, p. 111624.

[43] Weekes, L. M. (2016) 'Multidisciplinary approach to reducing pharmaceutical misuse', Medical Journal of Australia, pp. 96-96. doi: 10.5694/mja15.01305.

[44] Whitten, B. H. et al. (1996) 'CURRENT TRENDS IN ENDODONTIC TREATMENT: REPORT OF A NATIONAL SURVEY', The Journal of the American Dental Association, pp. 1333-1341. doi: 10.14219/jada.archive.1996.0444.

[45] Wu, F. et al. (2019) 'Biologically synthesized green gold nanoparticles from Siberian ginseng induce growth-inhibitory effect on melanoma cells (B16)', Artificial cells, nanomedicine, and biotechnology, 47(1), pp. 32973305.

[46] Attar, S. et al. (2008) 'Evaluation of Pretreatment Analgesia and Endodontic Treatment for Postoperative Endodontic Pain', Journal of Endodontics, pp. 652 655. doi: 10.1016/j.joen.2008.02.017.

[47] Becker, D. E. and Phero, J. C. (2005) 'Drug Therapy in Dental Practice: Nonopioid and Opioid Analgesics', Anesthesia Progress, pp. 140-149. doi: 10.2344/00033006(2005)52[140:dtd]2.0.co;2.

[48] Buck, D. et al. (2000) 'What makes a good dentist and do recent trainees make the grade? The views of vocational trainers', British Dental Journal, pp. 563-566. doi: 10.1038/sj.bdj.4800829a.

[49] Dionne, R. A. et al. (1983) 'Suppression of Postoperative Pain by Preoperative Administration of Ibuprofen in Comparison to Placebo, Acetaminophen, and Acetaminophen Plus Codeine', The Journal of Clinical Pharmacology, 
pp. 37-43. doi: 10.1002/j.15524604.1983.tb02702.x.

[50] Fernandes, M. and Ataide, I. (2010) 'Nonsurgical management of periapical lesions', Journal of Conservative Dentistry, p. 240. doi: 10.4103/0972-0707.73384.

[51] Germack, M. et al. (2017) 'Antibiotic Use in 2016 by Members of the American Association of Endodontists: Report of a National Survey', Journal of Endodontics, pp. $1615-1622$.

doi:

10.1016/j.joen.2017.05.009.

[52] Keiser, K. and Hargreaves, K. M. (2002) 'Building effective strategies for the management of endodontic pain', Endodontic Topics, pp. 93105. doi: 10.1034/j.16011546.2002.30109.x.

[53] Kia, S. J. et al. (2013) 'Evaluation of Drug Prescription Pattern among General Dental Practitioners in Rasht, Iran', Journal of Dentomaxillofacial Radiology, Pathology and Surgery, pp. 18-23. doi: 10.18869/acadpub.3dj.1.2.18.

[54] Kumar, K. P. et al. (2013) 'Antibiotic Prescribing Habits of Dental Surgeons in Hyderabad City, India, for Pulpal and Periapical
Pathologies: A Survey', Advances in Pharmacological Sciences, pp. 14. doi: 10.1155/2013/537385.

[55] Mainjot, A. et al. (2009) 'Antibiotic prescribing in dental practice in Belgium', International Endodontic Journal, pp. 1112-1117. doi: 10.1111/j.1365-2591.2009.01642.x.

[56] Narayanan, L. and Vaishnavi, C. (2010) 'Endodontic microbiology', Journal of Conservative Dentistry, p. 233. doi: 10.4103/09720707.73386.

[57] Rousseau, W. et al. (2002) 'A Comparison of Pain Levels During Pulpectomy, Extractions, and Restorative Procedures', Journal of Endodontics, pp. 108-110. doi: 10.1097/00004770-20020200000015 .

[58] Sarkar, C., Das, B. and Baral, P. (2004) 'Analgesic use in dentistry in a tertiary hospital in western Nepal', Pharmacoepidemiology and Drug Safety, pp. 729-733. doi: 10.1002/pds.972.

[59] Siqueira, J. F. and Rôças, I. N. (2014) 'Present status and future directions in endodontic microbiology', Endodontic Topics, pp. 3-22. doi: 10.1111/etp.12060. 
[60] Siqueirajr, J. and Rocas, I. (2005) 'Exploiting Molecular Methods to Explore Endodontic Infections: Part 2-Redefining the Endodontic Microbiota', Journal of Endodontics, pp. 488-498. doi: 10.1097/01.don.0000157990.86638. 49.

[61] Slaus, G. and Bottenberg, P. (2002) 'A survey of endodontic practice amongst Flemish dentists', International Endodontic Journal, pp. 759-767. doi: 10.1046/j.13652591.2002.00564.x.

[62] Weekes, L. M. (2016) 'Multidisciplinary approach to reducing pharmaceutical misuse', Medical Journal of Australia, pp. 96-96. doi: 10.5694/mja15.01305.

[63] Whitten, B. H. et al. (1996) 'Current Trends In Endodontic Treatment: Report Of A National Survey', The Journal of the American Dental Association, pp. 1333-1341. doi: 10.14219/jada.archive.1996.0444. 